PREHOSPITAL CARE

\title{
Results of an evaluation of the effectiveness of triage and direct transportation to minor injuries units by ambulance crews
}

\author{
H Snooks, T Foster, J Nicholl
}

Emerg Med J 2004;21:105-111

\begin{abstract}
Objective: To evaluate triage and transportation to a minor injury unit (MIU) by emergency ambulance crews.

Methods: Ambulance crews in two services were asked to transport appropriate patients to MIU during randomly selected weeks of one year. During all other weeks they were to treat such patients according to normal practice. Patients were followed up through ambulance service, hospital and/or MIU records, and by postal questionnaire. Semi-structured interviews were undertaken with crews $(n=15)$. Cases transferred from MIU to accident and emergency (A\&E) were reviewed. Results: 41 intervention cluster patients attended MIU, 303 attended A\&E, 65 were not conveyed. Thirty seven control cluster patients attended MIU, 327 attended A\&E, 61 stayed at scene. Because of low study design compliance, outcomes of patients taken to MIU were compared with those taken to A\&E, adjusted for case mix. MIU patients were 7.2 times as likely to rate their care as excellent $(95 \% \mathrm{Cl} 1.99$ to 25.8$)$. Ambulance service job-cycle time and time in unit were shorter for MIU patients $(-7.8,95 \% \mathrm{Cl}-11.5$ to $-4.1) ;(-222.7,95 \% \mathrm{Cl}-331.9$ to -123.5$)$. Crews cited patient and operational factors as inhibiting MIU use; and location, service, patient choice, job-cycle time, and handover as encouraging their use. Of seven patients transferred by ambulance from MIU to A\&E, medical reviewers judged that three had not met the protocol for conveyance to MIU. No patients were judged to have suffered adverse consequences. Conclusions: MIUs were only used for a small proportion of eligible patients. When they were used, patients and the ambulance service benefited.
\end{abstract}

See end of article for authors' affiliations

Accepted for publice
2 October 2003

Correspondence to:

Dr H Snooks, Clinica

Wales Swansea, Singleton

Park, Swansea SA2 8PP,

UK; h.a.snooks@swan.

ac.uk

...................... t is recognised that ambulance service emergency (999)

workload is diverse, and that a substantial proportion of calls are neither life threatening nor serious. As in the accident and emergency (A\&E) department, there is sometimes a mismatch between patients' clinical needs and response provided, ${ }^{1-4}$ with the rate of inappropriate emergency ambulance use reported as being between $11 \%$ and $52 \%{ }^{5}$ Ambulance services have begun to develop a range of responses for non-serious calls, such as the provision of telephone advice, ${ }^{6}$ the use of "Treat and Refer protocols", and the despatch of alternative vehicles. ${ }^{8}$ These may bring more appropriate care to callers at the least urgent end of the range while allowing a faster response to those with life threatening conditions.

Given suitable protocols, minor injury units (MIUs) may be an appropriate destination for some 999 patients. These are first contact services usually based around primary care, and require no appointment to attend. They differ from A\&E departments in that they are nurse led, with access to general practitioners (GPs) in some cases, and they are not open 24 hours a day, although they often offer extended opening hours including evenings and weekends. The scope of work carried out depends on facilities available, the qualifications and experience of staff, and the organisational links with a major A\&E department.

It has been proposed that judgment skills of paramedics should be increased to enable them to decide whether to bypass local care facilities to go to more appropriate care facilities. ${ }^{9-11}$ To date, there has been little research concerning the abilities of crews to triage patients to alternative receiving units, although two studies have pointed to the complexity of this change in practice ${ }^{12}{ }^{13}$ and a recent review concluded that evidence concerning the safety and effectiveness of alternative models is lacking. ${ }^{14}$

Taking patients to MIU may bring potential benefits to patients such as reduced waiting times and a shorter distance to travel home. However, there are concerns that triage mistakes could occur, which may result in inappropriate patients being taken to MIUs. Such patients would subsequently need to be transferred to A\&E, thereby delaying access to definitive care.

In summary, research evidence consistently points to use of emergency services by patients with non-urgent needs. MIUs may offer an alternative receiving unit for appropriate patients, and shorter waiting times and high patient satisfaction have been shown to be associated with MIU attendance. However, studies looking at the abilities of ambulance staff to appropriately triage patients to alternative models of care have been inconclusive. Inconsistencies in practice as well as risk of adverse outcome have been highlighted in several studies, although research methods used have been comparatively weak. ${ }^{14}$ In addition, the operational and clinical consequences of ambulance service triage and transportation to MIU have not been explored.

\section{STUDY OBJECTIVES}

- To evaluate the effectiveness of triage and direct transportation of patients to MIUs by ambulance crews in terms of:

Abbreviations: MIU, minor injury unit; SAS, Surrey Ambulance Service; LAS, London Ambulance Service; A\&E, accident and emergency 
- Ambulance performance

- Patient satisfaction

- Clinical safety

- To describe factors reported by crews as encouraging or inhibiting MIU use

\section{DESIGN}

The main study was designed as a cluster randomised controlled trial. After training, for a one year period ambulance crews were asked to use protocols to transport patients who met specific criteria to an MIU during randomly selected intervention weeks (totalling six months). During all other weeks such patients were to be treated according to normal practice, forming the control group. Standard practice was to transport patients who consented to travel to A\&E. At the time of the trial, crews in the two services did not normally have protocols to take patients to MIUs, although various initiatives had been and were underway before the study and during the study in other areas of the services.

\section{RESEARCH SETTING AND METHODS}

The study was conducted with ambulance crews $(n=55)$ at five ambulance stations in the London and Surrey Ambulance Services (LAS and SAS), with three participating MIUs in the catchment areas of those stations. The subjects were 999 patients, attended by participating ambulance crews, who fell within an agreed list of dispatch criteria that were judged to cover all potential cases of minor injury, and who were assessed as matching protocols for transportation to an MIU by the study paramedic, on retrospective review of patient report forms completed by the attending crew. This paramedic was blinded to the group to which the week in which the case occurred was allocated.

The study protocol was written to be acceptable to all the three participating MIUs (see box). Patients were unaware of the study and were allocated to either the intervention or control group according to the date of their call. Subjects were followed up through ambulance service, hospital and/or MIU records, and by postal questionnaire. The patient questionnaire used was based on the UK version of the Parkside Emergency Room Quality of Care Monitor. ${ }^{15}$ Three versions were produced for patients conveyed to A\&E, MIU, or not conveyed. All versions contained items about reasons for the 999 call and satisfaction with the ambulance service. For patients conveyed to A\&E or MIU, additional information about satisfaction with care received in the unit, preparation for returning home, time spent in the unit, and transport home were also requested.

All patients taken to MIU and transferred on to the A\&E department were reviewed by two A\&E consultants. From prehospital, A\&E, and MIU records, opinion was sought on whether:

- the patient was within the protocols for transportation to MIU

- the crew decision to take the patient to MIU was appropriate

- the transfer on to A\&E was appropriate, and why

- the condition or outcome of the patient was adversely affected by their initial conveyance to MIU rather than A\&E

Patients who were treated and discharged from the MIU were not further reviewed as we were not attempting to evaluate care at the MIU.

All participating ambulance crews and MIU nurses attended 1 of 14 project training sessions, covering an
Criteria for transportation to MIU during study period

Hours accepting ambulance borne patients 0900-1600 Mon-Fri

Technicians and paramedics may transport patients with minor injuries (not illnesses) who are outside the exclusion criteria detailed below to MIU

- Clinical suggestion of any head injury or GCS less than 15

- Chest, head, or abdominal pain

- Difficulty in breathing/swallowing

- Chest, abdominal pelvic, or eye injuries

- Spinal or neck injuries

- Complicated or compound fractures and those where bones protrude

- Long bone fractures

- Fractured clavicle

- Uncontrollable haemorrhage

- Burns greater than $1 \%-2 \%$ where injury to the airway cannot be excluded

- Burns greater than $5 \%$ on any part of the body

- Deep burns

- Secondary or circular burns of the limbs

- Burns to face, neck, or genitalia

- Electrical burns

- CVA, diabetes, epilepsy, asthma catheterisaton, or epistaxis

- Bites or reactions that are not controllable with adrenaline

- Any injury with a major trauma mechanism

- Women in the third trimester of pregnancy

- Patients under 5 years of age

- Patients whose behaviour may be detrimentally affected because of alcohol or drug use

- Patients with self inflicted injuries or any other psychiatric emergency

- All RTA and assault injuries

overview of the research background and methods; the MIU project in detail; and issues the staff thought were important. Throughout the study, close contact was maintained with crews and local managers, through Project Steering Group meetings, site visits, and study newsletters.

In addition, to explore patterns of MIU use, semistructured interviews were undertaken with crews $(n=15)$. A content analysis approach was taken to identify themes emerging from the interviews.

Ethical approval for the study was granted by the Multi Centre Research Ethics Committee and by 10 local research ethics committees responsible for the A\&E and MIU sites that took part in the study.

\section{RESULTS}

A total of 409 patients were recruited during intervention weeks and 425 during control weeks. The proportion of patients meeting the criteria for conveyance to MIU who were taken there was low, and in addition, the proportion of patients taken to MIU during control and intervention weeks was almost the same $(8.7 \%$ compared with $10.0 \%$ respectively) (table 1). This picture was similar in London and 


\begin{tabular}{|c|c|c|c|c|c|c|}
\hline \multirow{2}{*}{$\begin{array}{l}\text { Destination } \\
\text { MIU }\end{array}$} & \multicolumn{2}{|c|}{ Intervention weeks (\%) } & \multicolumn{2}{|c|}{ Control weeks (\%) } & \multicolumn{2}{|c|}{ Total (\%) } \\
\hline & 41 & $(10.0)$ & 37 & (8.7) & 78 & (9.4) \\
\hline A\&E & 303 & (74.1) & 327 & (76.9) & 630 & (75.5) \\
\hline Not conveyed & 65 & (15.9) & 61 & (14.4) & 126 & $(29.6)$ \\
\hline Total & 409 & $(100.0)$ & 425 & $(100.0)$ & 834 & $(100.0)$ \\
\hline
\end{tabular}

Surrey, in terms of overall use of MIUs and in terms of compliance with the research protocol. Patterns of conveyance were strikingly different, however, in that a significant proportion of patients were left at scene in London (31.4\%) whereas in Surrey nearly all patients were conveyed to A\&E or MIU $(98.9 \%)$.

Of the 834 patients recruited into the study, 43 had insufficient details for follow up. Thus, a total of 791 follow up packs were sent and of these 559 responses were received, 473 resulting in a completed questionnaire This gave an overall response rate of $70.7 \%$, and a completion rate of $59.8 \%$.

There were no significant differences between responders and non-responders for age, sex, study group, or between patients taken to MIU and A\&E. However, there were significant differences in the proportion of responders between MIU patients and patients that were not conveyed $\left(81.1 \%\right.$ versus $59.8 \%$ respectively, $\chi^{2}=9.04, \quad \mathrm{df}=1$, $\mathrm{p}=0.003)$, and between A\&E patients and patients that were not conveyed $(71.2 \%$ versus $59.8 \%$ respectively, $\left.\chi^{2}=5.39, \mathrm{df}=1, \mathrm{p}=0.027\right)$. Patients attended by SAS were more likely to respond than those attended by LAS $(77.4 \%$ versus $62.2 \%$ respectively, $\left.\chi^{2}=21.87, \mathrm{df}=1, \mathrm{p}=0.000\right)$.

As a result of low compliance with the study design, outcomes were compared for patients taken to MIU with those taken to A\&E, rather than by study group as originally planned. Comparisons were adjusted for factors found to influence patient destination.

The biggest influence on choice of patient destination was distance from the incident to where the patient was taken. With this taken into account the distance to the nearest other type of facility, the time of day (in or out of hours), whether the patient had a head injury, the patient's sex, and the service involved (LAS/SAS) all continued to significantly influence choice of destination but there was no evidence that the randomisation schedule affected the destination (table 2).
These factors were used to adjust the case mix when comparing outcomes (tables 3 and 4). Ambulance service job cycle time, time to treatment, and total time in unit were shorter for patients taken to MIU than for patients taken to A\&E $(-7.8,95 \%$ CI:-1 1.5 to -4.1$)$; $(-84.6,95 \%$ CI: -108.1 to -61.1$)$; $(-222.7,95 \% \mathrm{CI}:-331.9$ to -123.5$)$ respectively. MIU patients were 7.2 times as likely to rate their overall care as excellent as A\&E patients (95\% CI:1.99 to 25.8).

Seven patients were taken to MIU and subsequently transferred by ambulance to A\&E during the study. Although the medical reviewers agreed that in three of these cases the patient did not meet the protocol for conveyance to MIU, in none of the cases did they judge that the condition or outcome of these patients suffered adversely as a result of initial conveyance to MIU. However, they did highlight three difficulties associated with implementing protocols to enable ambulance crews to convey patients to alternative destinations other than A\&E. Firstly, patients may choose to attend MIU or refuse $A \& E$ despite A\&E being the appropriate destination. This may prove difficult for crews to negotiate. Secondly, injuries that apparently meet protocols for transportation to MIU may turn out to have gone to MIU inappropriately after further investigation. Finally, crews may miss injuries or be misled by patients about the nature of their injuries (table 5).

The first level of analysis of crew interview transcripts indicated 26 categories related to crews deciding not to convey to MIU, and 18 categories related to crews deciding to convey to MIU. The second level of analysis combined similar categories to reveal a smaller number of themes. At this level, nine factors hindered crew conveyance to MIU, and seven factors encouraged conveyance to MIU. Operational factors such as distance to MIU compared with A\&E, uncertainty about patients being acceptable to the MIU, opening times of MIUs, and restrictive MIU protocols were frequently men-

Table 2 Characteristics possibly affecting destination (A\&E or MIU)

\begin{tabular}{|c|c|c|c|c|c|c|}
\hline Characteristic & Test $^{*} \chi^{2}$ & $d f$ & p Value & Test† $\mathbf{G}^{2}$ & $d f$ & p Value \\
\hline In or out of hours & 7.34 & 1 & 0.01 & 5.25 & 1 & 0.02 \\
\hline Day of week & 9.17 & 6 & 0.17 & 7.85 & 6 & 0.25 \\
\hline Month & 9.1 & 11 & 0.61 & 6.70 & 11 & 0.82 \\
\hline Age of patient & 0.61 & 1 & 0.44 & 2.0 & 1 & 0.16 \\
\hline Sex of patient & 2.39 & 1 & 0.12 & 4.46 & 1 & 0.04 \\
\hline Service (LAS/SAS) & 0.04 & 1 & 0.84 & 21.4 & 1 & 0.00 \\
\hline $\begin{array}{l}\text { Place of incident (home } v \\
\text { other) }\end{array}$ & 0.41 & 1 & 0.52 & 1.09 & 1 & 0.30 \\
\hline Head injury & 7.47 & 1 & 0.01 & 5.41 & 1 & 0.02 \\
\hline Fall & 0.01 & 1 & 0.94 & 0.54 & 1 & 0.46 \\
\hline Distance to actual destination & 135.6 & 1 & 0.00 & - & & \\
\hline $\begin{array}{l}\text { Distance to nearest opposite } \\
\text { type of facility }\end{array}$ & 13.3 & 1 & 0.00 & 38.0 & 1 & 0.00 \\
\hline $\begin{array}{l}\text { Relative distance (actual- } \\
\text { opposite) }\end{array}$ & 88.0 & 1 & 0.00 & 38.0 & 1 & 0.00 \\
\hline Randomisation group & 0.56 & 1 & 0.46 & 0.24 & 1 & 0.62 \\
\hline
\end{tabular}

*Pearson $\chi^{2}$ test or binary logistic regression for association between characteristic and destination; tbinary logistic regression adjusting for distance to actual destination. 
Table 3 Summary of key performance measures: crude and case mix adjusted comparisons between the MIU and A\&E groups

\begin{tabular}{|c|c|c|c|c|c|}
\hline \multirow{3}{*}{$\begin{array}{l}\begin{array}{l}\text { Performance } \\
\text { measure (min) }\end{array} \\
\text { AS job time (999 } \\
\text { call to "job } \\
\text { finished" time) }\end{array}$} & \multicolumn{3}{|c|}{ Unadjusted comparisons } & \multicolumn{2}{|c|}{ Adjusted comparisons } \\
\hline & \multirow{2}{*}{$\begin{array}{l}\text { p Value } \\
0.00\end{array}$} & \multicolumn{2}{|c|}{$\begin{array}{l}\text { Estimated effect of MIU } \\
\text { compared with A\&E }(95 \% \mathrm{CI})\end{array}$} & \multirow{2}{*}{$\begin{array}{l}\text { p Value } \\
0.00\end{array}$} & $\begin{array}{l}\text { Estimated effect of MIU } \\
\text { compared with A\&E }(95 \% \mathrm{CI})\end{array}$ \\
\hline & & -12.6 & $(-16.3$ to -8.97$)$ & & $-7.8 \quad(-11.5$ to -4.1$)$ \\
\hline $\begin{array}{l}\text { Time to treatment } \\
\text { (arrival at unit to } \\
\text { time seen by } \\
\text { doctor) }\end{array}$ & 0.00 & -89.1 & $(-110.6$ to -67.6$)$ & 0.00 & $-84.6 \quad(-108.1$ to -61.1$)$ \\
\hline $\begin{array}{l}\text { Total time in unit } \\
\text { (arrival at unit to } \\
\text { time left unit) }\end{array}$ & 0.00 & -208.4 & $(-305.6$ to -111.2$)$ & 0.00 & $-227.7 \quad(-331.9$ to -123.5$)$ \\
\hline
\end{tabular}

tioned as factors for not transporting patients to MIU. In addition, patient factors such as age, underlying medical condition, and choice were also mentioned as factors for not transporting to MIU. Despite low use, some factors were mentioned that crews reported might lead to transportation to MIU: location, perceived positive differences in service delivery at MIU compared with A\&E, patient needs and choice, reduced job-cycle times, and improved handover. The study design of randomised intervention weeks seemed to cause confusion about when to transport patients to MIU (table 6).

\section{DISCUSSION}

\section{Key findings}

In both study sites the participating crews used the MIUs for only a small proportion of patients who appeared to be suitable for MIU treatment. The most important factor influencing the decision to take a patient to MIU was its location in relation to the incident. When the MIUs were used, the ambulance service and patients benefited in terms of job cycle time, waiting time, and satisfaction with care.

\section{Study limitations}

An important limitation to the interpretation of findings from this study was the failure of the study design. The crews in both participating services seemed to take several factors into account when deciding where to convey a patient, but not the randomisation schedule. Patients were equally likely to be taken to an MIU during the control weeks, when, according to the study protocol, patients were only to be taken to the local A\&E, according to standard practice. This lack of compliance meant that the analysis plans had to be amended. The planned comparisons between the intervention and control groups simply would not be able to demonstrate any costs or benefits associated with the new treatment protocols allowing crews to triage and transport patients directly to MIU.

In this study, the research team were very familiar with the ambulance service setting. Because of experience on earlier trials with ambulance personnel, pre-trial training was provided for participating crews. This training focused on research methods-and the need for a control group—so that comparisons could be made on the study outcomes. In addition, extensive consultation was undertaken at the outset of the study with local crews and managers in London and Surrey. There was no indication of dissent at any stage. Practically, it proved difficult to find reliable systems of reminding crews whether the week was one in which their MIU protocols could be used or not. However, this level of non-compliance cannot be explained by some forgetfulness. Crews simply seemed not to take into account the randomisation schedule when deciding upon the destination of any individual patient.

Response rates were not high, although they were probably as high as can be expected in a study of this group of patients. Nevertheless, the patients who did not respond may not have held the same views as those that did, and this should be taken into account when interpreting results. Response rates did not differ between the MIU and A\&E groups and seem unlikely therefore, to affect the comparisons made between satisfaction levels in the two groups.

\section{General discussion}

As is common in evaluative studies, the intervention being assessed was introduced alongside the evaluation. This permitted no "bedding down" or familiarisation period and although use of MIUs during the study was found to be low this could change over time. Many change management issues were raised by crews during the qualitative interviews-such as lack of confidence in MIU acceptance of patients that they transport there-which might be resolved over time.

Despite overall low use of the MIUs, a minority of patients were inappropriately taken to MIU, resulting in subsequent transfer to A\&E. Although in this study, none of these were judged to have suffered an adverse outcome as a result of the original mis-triage, the sample size was small and this possibility cannot be excluded if the policy were to become routine. Crews may need more clinical training to reduce the likelihood of patients being inappropriately conveyed to MIU.

Table 4 Case mix adjusted patient reported satisfaction

\begin{tabular}{|c|c|c|c|}
\hline \multirow{2}{*}{$\begin{array}{l}\text { Patient } \\
\text { reported } \\
\text { outcomes }\end{array}$} & \multirow{2}{*}{$\begin{array}{l}\begin{array}{l}\text { Unadjusted } \\
\text { comparison }\end{array} \\
\mathrm{p} \\
\text { Value }\end{array}$} & \multicolumn{2}{|c|}{ Adjusted comparison } \\
\hline & & $\begin{array}{l}\text { p } \\
\text { Value }\end{array}$ & $\begin{array}{l}\text { Estimated odds for MIU patients } \\
\text { versus A\&E patients }(95 \% \mathrm{Cl})\end{array}$ \\
\hline $\begin{array}{l}\text { Ambulance } \\
\text { care }\end{array}$ & 0.67 & 0.97 & $\begin{array}{l}\text { "excellent" versus other: }=0.99 \\
\text { (0.46 to } 2.09 \text { ) }\end{array}$ \\
\hline $\begin{array}{l}\text { Satisfaction } \\
\text { with outcome } \\
\text { of treatment }\end{array}$ & 0.12 & 0.13 & $\begin{array}{l}\text { "satisfied" versus "not satisfied" } \\
=2.46(0.53 \text { to } 11.6) \\
\text { "satisfied to some extent" versus } \\
\text { "not satisfied" }=1.00 \text { (0.17 to } \\
5.79)\end{array}$ \\
\hline $\begin{array}{l}\text { Overall } \\
\text { quality of } \\
\text { care }\end{array}$ & 0.00 & 0.001 & $\begin{array}{l}\text { "excellent" versus "fair or poor" } \\
=7.17 \text { (1.99 to } 25.8) \\
\text { "good" versus "fair or poor" } \\
=2.74(0.72 \text { to } 10.5)\end{array}$ \\
\hline
\end{tabular}


Table 5 Patients taken to MIU and transferred by ambulance to A\&E: case review

\begin{tabular}{|c|c|c|c|c|}
\hline Patient details & $\begin{array}{l}\text { Patient within protocols } \\
\text { for transportation to MIU? }\end{array}$ & Crew decision appropriate? & $\begin{array}{l}\text { Transfer on to A\&E } \\
\text { appropriate? }\end{array}$ & $\begin{array}{l}\text { Condition/outcome of patient } \\
\text { adversely affected by initial } \\
\text { conveyance to MIU? }\end{array}$ \\
\hline $\begin{array}{l}\text { 0323: } 74 \text { year old woman, } \\
\text { fallen at home. Presented with } \\
\text { pain and swelling in her right } \\
\text { ankle, and was not weight } \\
\text { bearing. A previous history of } \\
\text { osteoporosis was recorded. }\end{array}$ & Both reviewers: yes & Both reviewers: yes & $\begin{array}{l}\text { Both reviewers: yes, } \\
\text { radiograph taken at the } \\
\text { MIU revealed a bi-malleolar } \\
\text { fracture with talar shift that } \\
\text { would need internal fixation, } \\
\text { therefore transfer to A\&E } \\
\text { was appropriate. }\end{array}$ & $\begin{array}{l}\text { Both reviewers: no. This patient } \\
\text { was treated at A\&E then } \\
\text { discharged home to attend } \\
\text { fracture clinic as an outpatient. }\end{array}$ \\
\hline $\begin{array}{l}\text { 0358: } 85 \text { year old woman, } \\
\text { fallen while crossing the road. } \\
\text { She presented the ambulance } \\
\text { crew with wounds to the face, } \\
\text { hand, and knee, but was } \\
\text { reluctant to divulge history } \\
\text { details. }\end{array}$ & Both reviewers: yes & $\begin{array}{l}\text { Both reviewers: yes, albeit } \\
\text { the patient giving limited } \\
\text { information hampered them }\end{array}$ & $\begin{array}{l}\text { Both reviewers: yes, staff } \\
\text { at MIU found it difficult to } \\
\text { stem the arterial bleed } \\
\text { from the hand wound; } \\
\text { therefore transfer to A\&E } \\
\text { was appropriate. }\end{array}$ & $\begin{array}{l}\text { Both reviewers: no. This patient } \\
\text { was treated at A\&E then } \\
\text { discharged home for follow up } \\
\text { by a district nurse. }\end{array}$ \\
\hline $\begin{array}{l}\text { 0576: } 65 \text { year old man who } \\
\text { had slipped at home. He } \\
\text { presented the ambulance crew } \\
\text { with a wound to the head, but } \\
\text { with no loss of consciousness. } \\
\text { The patient refused A\&E but } \\
\text { was persuaded to seek some } \\
\text { medical attention at MIU. }\end{array}$ & $\begin{array}{l}\text { Medical opinion was } \\
\text { divided whether this } \\
\text { patient met the protocol } \\
\text { for transportation to MIU }\end{array}$ & $\begin{array}{l}\text { Reviewers did not agree on } \\
\text { whether the crew decision to } \\
\text { take the patient to MIU was } \\
\text { appropriate. The subsequent } \\
\text { admission by the patient of } \\
\text { loss of consciousness for } 15 \\
\text { minutes made one reviewer } \\
\text { conclude that MIU was not } \\
\text { appropriate. However, it was } \\
\text { only at MIU that the loss of } \\
\text { consciousness was } \\
\text { discovered therefore the } \\
\text { second reviewer concluded } \\
\text { that MIU was appropriate in } \\
\text { the face of patient reluctance } \\
\text { to attend A\&E. }\end{array}$ & Both reviewers: yes & $\begin{array}{l}\text { Both reviewers: no. This patient } \\
\text { was treated at A\&E then } \\
\text { discharged home for follow } \\
\text { up by GP. }\end{array}$ \\
\hline $\begin{array}{l}0701: 67 \text { year old woman } \\
\text { who had fallen. She } \\
\text { presented the ambulance crew } \\
\text { with a suspected fracture of the } \\
\text { wrist and insisted on attending } \\
\text { MIU. }\end{array}$ & Both reviewers: yes & Both reviewers: yes & $\begin{array}{l}\text { Both reviewers: yes, a } \\
\text { radiograph taken at the } \\
\text { MIU revealed a Colles } \\
\text { fracture that needed } \\
\text { manipulation; therefore } \\
\text { transfer to A\&E was } \\
\text { appropriate. }\end{array}$ & $\begin{array}{l}\text { Both reviewers: no. This patient } \\
\text { was treated at } A \& E \text { then } \\
\text { discharged home to attend } \\
\text { fracture clinic as an outpatient. }\end{array}$ \\
\hline $\begin{array}{l}\text { 0728: } 86 \text { year old woman } \\
\text { who had fallen while getting } \\
\text { off a bus. She presented the } \\
\text { ambulance crew with a } \\
\text { wound to the head. }\end{array}$ & $\begin{array}{l}\text { Both reviewers: no, } \\
\text { because she was elderly } \\
\text { with pain in her hip and } \\
\text { not weight bearing as } \\
\text { well as having a head } \\
\text { wound }\end{array}$ & $\begin{array}{l}\text { One reviewer noted that } \\
\text { the crew decision to take } \\
\text { the patient to MIU was } \\
\text { appropriate because it was } \\
\text { very close. }\end{array}$ & $\begin{array}{l}\text { Both reviewers: yes, staff } \\
\text { at MIU treated the head } \\
\text { wound but suspected a } \\
\text { fractured neck of femur; } \\
\text { therefore transfer to A\&E } \\
\text { was appropriate }\end{array}$ & $\begin{array}{l}\text { Both reviewers: no. A radiograph } \\
\text { taken at A\&E revealed a fractured } \\
\text { greater trochanter. This patient } \\
\text { required physiotherapy and was } \\
\text { admitted to an orthopaedic ward. }\end{array}$ \\
\hline $\begin{array}{l}0731: 89 \text { year old woman who } \\
\text { had tripped and fallen at home. } \\
\text { She presented the ambulance } \\
\text { crew with bruising of the } \\
\text { forehead and neck and arm } \\
\text { pain, and insisted on } \\
\text { attending MIU. }\end{array}$ & Both reviewers: no & $\begin{array}{l}\text { Both reviewers: yes, the } \\
\text { crew had no choice other } \\
\text { than taking the patient to } \\
\text { MIU because the patient } \\
\text { insisted on that }\end{array}$ & $\begin{array}{l}\text { Both reviewers: yes, } \\
\text { transfer to A\&E was } \\
\text { appropriate due to the } \\
\text { nature of the injuries. }\end{array}$ & $\begin{array}{l}\text { Both reviewers: no. This patient } \\
\text { was treated at A\&E and } \\
\text { discharged home. }\end{array}$ \\
\hline $\begin{array}{l}0884: 73 \text { year old woman } \\
\text { who had vomited after a train } \\
\text { journey. She was reluctant to } \\
\text { attend A\&E. }\end{array}$ & Both reviewers: no & $\begin{array}{l}\text { Both reviewers: yes, the } \\
\text { ambulance crew decision } \\
\text { to take the patient to MIU } \\
\text { was a compromise } \\
\text { because of the reluctance } \\
\text { to attend A\&E. }\end{array}$ & $\begin{array}{l}\text { Both reviewers: yes, the } \\
\text { nature of the condition } \\
\text { meant that transfer to A\&E } \\
\text { was appropriate. }\end{array}$ & $\begin{array}{l}\text { Both reviewers: no. This patient } \\
\text { underwent investigations at A\&E } \\
\text { but did not wait for results and } \\
\text { self discharged against medical } \\
\text { advice. }\end{array}$ \\
\hline
\end{tabular}

The non-compliance we have found in this study mirrors that reported before in previous work. ${ }^{76}{ }^{17}$ Partial randomisation of paramedic crews to appropriate cases was planned in Nicholl's 1998 evaluation of paramedic skills for serious trauma, although in the event only 185 were randomly allocated to paramedic or technician response. Of these, only 16 met the study inclusion criteria and could be included in the total sample of 2045 for analysis of outcomes. ${ }^{16}$ A further study by the same team, published in 2000, used a study design of two protocols for intravenous fluids in serious trauma, to which appropriate patients should have been randomly allocated. Again, compliance was low, particularly in the cases of most interest, those with serious injury, or in a serious condition on scene. ${ }^{17} \mathrm{~A}$ trial of telephone advice for non-serious 999 callers also suffered from low compliance on the part of call takers who did not pass over all calls falling within study inclusion criteria to the nurse and paramedic advisors, but selected calls they felt might benefit from advice. ${ }^{7}$ The dearth of randomised controlled trials in prehospital care research has been lamented, ${ }^{18-20}$ but our experience in several studies has been that compliance with research protocols can be low in this area of research, and study design should be considered carefully at the planning stages of any study.

\section{Conclusions}

Study design needs to be carefully considered in prehospital care research. It is not always apparent that personnel will not comply fully with study protocols, but experience suggests that randomisation is difficult to 
Table 6 Factors reported by crews to encourage or hinder transportation to MIU with quotes

\begin{tabular}{|c|c|c|}
\hline Factor & \multirow{2}{*}{$\begin{array}{l}\text { Frequency of } \\
\text { reporting }\end{array}$} & \multirow[b]{2}{*}{ Example: quote } \\
\hline Hindering conveyance & & \\
\hline Distance & 11 & $\begin{array}{l}\text { "This particular case, we didn't take him to W because he lived in F, so way out of the way to take him all } \\
\text { the way to W for just a cut on the back of the hand." }\end{array}$ \\
\hline \multicolumn{3}{|r|}{ T } \\
\hline $\begin{array}{l}\text { - restrictive protocols } \\
\text { - study design }\end{array}$ & $\begin{array}{r}11 \\
8\end{array}$ & "The only problem that we've said all along is what we can take [to MIU]. We're quite restricted." \\
\hline $\begin{array}{l}\text { - lack of training in } \\
\text { protocol use }\end{array}$ & 3 & $\begin{array}{l}\text { "It has been a bit confusing I must admit. I know some people have got confused with which is which. But it is } \\
\text { very difficult to do this control and intervention week. I understand why it was needed for the study but at the } \\
\text { end of the day the patient is more important and what happens to them. I feel that even though it may not be } \\
\text { the right week if they need to go then it's best for the patient." }\end{array}$ \\
\hline Facilities at MIU & 11 & $\begin{array}{l}\text { "I know from experience at W that they can overview X-rays, whereas at } \mathrm{H} \text { I believe they can't, they're } \\
\text { relying on a GP to look at the X-rays. That's not running them down it's just a statement of fact." }\end{array}$ \\
\hline MIU staff support & 11 & $\begin{array}{l}\text { "But even when we felt it could possibly go to [MIU] there was the aspect of the staff there. I didn't feel they } \\
\text { were supporting the project. They are nice people but I felt it was seen as extra work for them and I think it } \\
\text { was hassle sorting out getting [patients] home." }\end{array}$ \\
\hline Time issues & & $\begin{array}{l}\text { "Opening times, well there is a variation but if [the MIUs were] open for longer it increases the chances of us } \\
\text { taking patients there clearly, but they must be regular hours each week." }\end{array}$ \\
\hline - opening times of the MIUs & 10 & \\
\hline $\begin{array}{l}\text { increased downtime (the } \\
\text { ambulance busy on a call) } \\
\text { if a patient was not accepted } \\
\text { by the MIU }\end{array}$ & 3 & \\
\hline $\begin{array}{l}\text { increased time to make } \\
\text { decisions about the } \\
\text { destination of a patient }\end{array}$ & 1 & \\
\hline $\begin{array}{l}\text { Patient characteristics, for } \\
\text { example, age/underlying } \\
\text { medical condition }\end{array}$ & 9 & $\begin{array}{l}\text { "This first one, this gentleman here, was picked up at a place for dementia patients. They wouldn't have } \\
\text { been able to cope with the condition of dementia [at MIU]." }\end{array}$ \\
\hline Patient choice & $?$ & $\begin{array}{l}\text { "The second [patient] definitely could have gone [to MIU] but through her own choice she wanted to go to } \\
\text { [A\&E] because it's nearer to home and she was being picked up by her son, therefore it was easier for her to } \\
\text { go to [A\&E]. It's only a couple of miles to her home." }\end{array}$ \\
\hline $\begin{array}{l}\text { Ambulance service issues } \\
\text { such as communication }\end{array}$ & 6 & $\begin{array}{l}\text { "So for instance we came in late on Tuesday to start work, we'd gone out on the road thinking shall we, } \\
\text { shan't we. And we asked Control are we on a control week or are we on an intervention week, and they } \\
\text { can't tell us because they claim they don't have the information." }\end{array}$ \\
\hline $\begin{array}{l}\text { Low numbers of appropriate } \\
\text { cases }\end{array}$ & 4 & $\begin{array}{l}\text { "Well one of the reasons why we didn't go there, we just never presented with anything appropriate on the } \\
\text { protocols to go. It's as simple as that." }\end{array}$ \\
\hline Litigation fears & 3 & $\begin{array}{l}\text { "The trouble is that in some respects you know there's always the thought in the back of crews minds about } \\
\text { litigation. If you take them to [MIU] and they should have gone to the main hospital will these people sue us } \\
\text { for taking them to the wrong hospital you know, and you've always got that in the back of your mind." }\end{array}$ \\
\hline \multicolumn{3}{|r|}{ 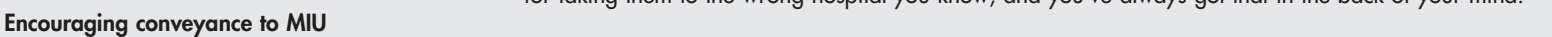 } \\
\hline Distance to MIU & 15 & $\begin{array}{l}\text { "Basically with the MIU, normally we decide to go there if it meets criteria, its minor injuries, and if it's } \\
\text { normally within W and nearer to the MIU." }\end{array}$ \\
\hline Reduced waiting time in MIU & 14 & $\begin{array}{l}\text { "The bottom line for patients is that they know they're going to end up waiting } 4 \text { to } 6 \text { hours in A\&E on a } \\
\text { number of occasions, so if you can offer them an alternative most of them I'm sure will take the bait." }\end{array}$ \\
\hline Valued resource & 8 & $\begin{array}{l}\text { "Basically I think [the MIUs] are a good idea. Whether or not after this year, you know I imagine everything } \\
\text { will still be in place, but whether the protocols will change or whatever, but I think we should use it more and } \\
\text { I think we will do." }\end{array}$ \\
\hline Clear meeting of protocols & 7 & $\begin{array}{l}\text { "Oh yes, I'd give [the MIU] a try. I mean somebody with just a wound on the back of the hand that probably } \\
\text { needed some steristrips or a person that's just got a small cut on her head and there's not any underlying } \\
\text { problem then I would go to the MIU first." }\end{array}$ \\
\hline Patient preference & 5 & $\begin{array}{l}\text { "That one there, the lady insisted on going to W [MIU] purely because her husband died at St Peters so she } \\
\text { didn't want to go there as an emergency... She was delighted that she could go there, absolutely delighted." }\end{array}$ \\
\hline Crew characteristics & 3 & $\begin{array}{l}\text { "Length of service. To be honest with you I think that being a younger crew, which we are, we are a bit more } \\
\text { flexible. The older members they've only known this is how we do it and that's it." }\end{array}$ \\
\hline $\begin{array}{l}\text { Reduced time to handover } \\
\text { at MIU }\end{array}$ & 3 & $\begin{array}{l}\text { "[The MIU] does us a lot because our turn around time is a lot better, and being in W you're literally minutes } \\
\text { away from the hospital, so yes I think it's a good idea." }\end{array}$ \\
\hline
\end{tabular}

achieve and the lower the reliance on participants to decide when to apply protocols, the more robust the study will be.

Although MIU use was lower than anticipated, benefits associated with their use have been identified to the ambulance service in terms of reduced distances travelled and reduced job-cycle times, and to patients in terms of reduced waiting time for treatment, overall time spent at the unit, and increased satisfaction.

After introduction of protocols that allow crews to use alternative receiving units many other factors may impede practice change and may need to be addressed before potential benefits are fully realised.

On balance, MIUs should be used for appropriate patients within locally defined catchment areas based on location of nearest alternative A\&E department.

\section{ACKNOWLEDGEMENTS}

We thank the participating ambulance crews, A\&E and MIU nurses and managers in London and Surrey. Thanks also to Chris HartleySharpe for his contribution to study design and project implementation. Finally thanks to Mr Tachakra, A\&E consultant at Central Middlesex Hospital for writing the study protocols and to Fionna Moore, medical director at the London Ambulance Service for her clinical contribution to the study.

\section{Contributors}

Helen Snooks was the grantholder and led the study, from its inception to interpretation and write up of findings. She is the guarantor for the paper. Theresa Foster managed the study and data collection and contributed to analysis of findings, interpretation and write up. Jon Nicholl contributed to the study at all stages, particularly with regard to study design and statistical analysis. All authors contributed to the writing of the paper. 


\section{Authors' affiliations}

H Snooks, Clinical School, University of Wales Swansea, UK

T Foster, London Ambulance Service NHS Trust, UK

J Nicholl, Medical Care Research Unit, University of Sheffield, UK

Funding: the study was funded by London Region NHS Executive.

Conflicts of interest: none declared.

\section{REFERENCES}

1 Palazzo FF, Warner OJ, Harron M, et al. Misuse of the London ambulance service: how much and why. J Accid Emerg Med 1998;15:368-70.

2 Chen JC, Bullard MJ, Liaw SJ. Ambulance use, misuse, and unmet needs in a developing emergency medical services system. European Journal of Emergency Medicine 1996;3:73-8.

3 Mann C, Guly H. Is the emergency (999) service being misused? BMJ 1998:316:437-8

4 Victor CR, Peacock JL, Chazot C, et al. Who calls 999 and why? A survey of the emergency workload of the London Ambulance Service. J Accid Emerg Med 1999; 16:174-8

5 Snooks H, Wrigley H, George S, et al. Appropriateness of use of emergency ambulances. J Accid Emerg Med 1998;15:212-18.

6 Dale J, Williams S, Foster T, et al. The clinical, organisational and cost consequences of computer-assisted telephone advice to category C 999 ambulance service callers: results of a controlled trial. Final Report 2000. Coventry: Centre of Primary Health Care Studies, School of Postgraduate Medicine, University of Warwick, Coventry, 2000.

7 Snooks H, Dale J, Kearsley N, et al. Development and impact of emergency ambulance 'Treat and Refer' protocols for non-serious 999 patients. Final Report 2001. Swansea: Centre for Postgraduate Studies, Swansea Clinical School, University of Wales Swansea, Singleton Park, Swansea, 2001.
8 Halter M, Hartley-Sharpe C, Lynch T. Blue light bicycles: evaluation of a cycle response unit (CRU) pilot scheme. Emerg Med J 2002;19:167.

9 Pencheon D. Opportunities in emergency health care. Cambridge: Department of Public Health Medicine, Anglia and Oxford Regional Health Authority, 24 May 1995.

10 NHS Executive. Developing Emergency Services in the Community. Final Report, 1998. London: NHS Executive, 1998

11 Department if Health. Reforming emergency care. London: Winter and Emergency Services Capacity Planning Team, Department of Health, 2001.

12 Kamper M, Mahoney BD, Nelson S, et al. Feasibility of paramedic treatment and referral of minor illnesses and injuries. Prehospital Emergency Care $2001 ; 5: 371-8$

13 Plorde M. Appropriate destination and patient treatment (ADAPT) pilot project. Final Report March 2001. Southeast Kent, WA: Valley Communications Centre, 2001.

14 Snooks H, Williams S, Dale J, et al. Alternatives to the standard emergency response for 999 ambulance service callers with problems that are neither life threatening not serious: a review of the literature. BMJ 2002;325:330-3.

15 Carey RC, Seibert JH. A patient survey system to measure quality improvement questionnaire reliability and validity. Med Care 1993;31:834-45.

16 Nicholl J, Hughes S, Dixon S, et al. The costs and benefits of paramedic skills in pre-hospital trauma care. Health Technol Assess 1998;2:17.

17 Turner J, Nicholl J, Webber L, et al. A randomised controlled trial of prehospital intravenous fluid replacement therapy in serious trauma. Health Technol Assess 2000;4:31.

18 Brice JH, Garrison HG, Evans AT. Study design and outcomes in out-ofhospital emergency medicine research: a ten-year analysis. Prehospital Emergency Care 2000:4:144-50.

19 Callaham M. Quantifying the scanty science of prehospital emergency care. Ann Emerg Med 1997;30:785-90.

20 Spaite DW, Criss EA, Valanzuela TD, et al. Emergency medical services system research: problems of the past, challenges of the future. Ann Emerg Med 1995;26:146-52. 